\title{
Clinical Forensic Evidence in Gunshot Wounds through Anesthesia and Surgical Procedures: A Case Report
}

\author{
Taufik Suryadi $^{1} \mathbb{D}$, Kulsum Kulsum $^{2 *} \mathbb{D}$, Ari Putra Simatupang ${ }^{3}$, Irhamni Rahmatillah ${ }^{3}$, Putri Mentari ${ }^{3}$, Raisha Fathima ${ }^{3}$ \\ ${ }^{1}$ Department of Forensic Medicine and Medico-legal, Faculty of Medicine, Universitas Syiah Kuala, Zainoel Abidin General \\ Hospital, Banda Aceh, Indonesia; ${ }^{2}$ Department of Anesthesiology and Intensive Therapy, Faculty of Medicine, Universitas \\ Syiah Kuala, Zainoel Abidin General Hospital, Banda Aceh, Indonesia; ${ }^{3}$ Medical Student of Forensic Medicine Clinical Rotation, \\ Faculty of Medicine, Universitas Syiah Kuala, Banda Aceh, Indonesia
}

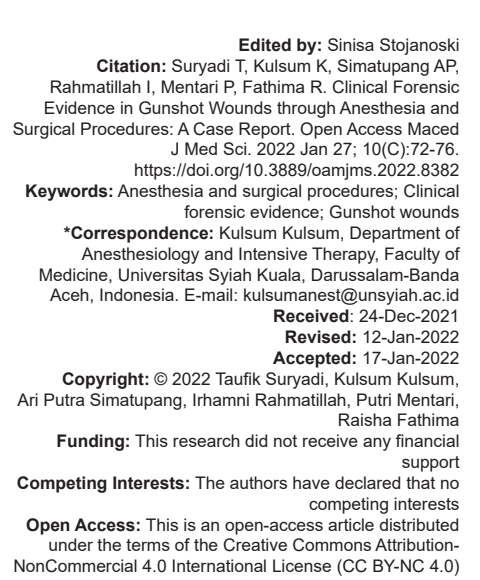

Abstract

BACKGROUND: Clinical forensic evidence of live victims with gunshot wounds can be supported by anesthesia and surgical procedures. Gunshot wounds are a complex and traumatic type of wound that are commonly found in forensic practice, most of which can cause death. Injuries to gunshot wounds are caused by the penetration of a projectile into the body that is ejected from the barrel of a gun due to the burning of gunpowder from the bullet. Using anesthetic procedures and thoracic surgery can help to prove the victim's gunshot wound. Medical evidence in the form of bullet projectiles found on the victim's body can be used as legal evidence. Hence, it can be said that anesthesia and thoracic surgery procedures can be one of the modalities of clinical forensic examination in proving the existence of a criminal event.

CASE REPORT: The method of this study was a case report. A 58-year-old male victim was shot in the left back. Forensic examination of the victim showed a gunshot wound to the left side of the back about the $11^{\text {th }}$ thoracic vertebra, round or oval in shape, accompanied by seams of abrasions around the wound, no seams of tattoos, soot or fire were found, and not accompanied by a gunshot wound. Based on the results of the radiographic examination of the posteroanterior and lateral chest radiographs, two cylindrical radio-opaque images were found in the left hemithorax. During anesthesia and thoracic surgery, a foreign body was found in the left thoracic wall region, as wel as lacerations in the left inferior lobe of the lung. Clinical forensic evidence in gunshot wounds has been successfully carried out using anesthesia and surgical procedures. The evidence was also reviewed from the radiologica examination which proved the existence of bullet projectiles by virtual imaging.

CONCLUSION: Clinical forensic evidence of course continues to evolve in accordance with advances in medical technology. The better the proof method, the easier it is to find the desired evidence. Anesthesia and surgical procedures can be used as an alternative to forensic evidence in clinical cases.

\section{Introduction}

Clinical forensics is a branch of forensic medicine that includes medicolegal assessments of living victims. Clinical forensics-related examinations assess medical findings in a context related to justice [1]. A number of modalities that support clinical forensic practice are anesthetic and surgical procedures, such as those performed on living victims with gunshot wounds in this case report. Gunshot wounds or ballistic trauma are complex and traumatic types of injuries that are commonly found in forensic practice, where a large percentage of events have the potential to cause death. Injuries to this gunshot wound were caused by the penetration of projectiles into the body that were ejected from the barrel of the gun due to the burning of munitions [2], [3], [4].

As evidence enforcement in forensic cases, a number of examinations need to be carried out. The examination is in the form of clinical forensic physical, radiological examination, and laboratory. Forensic examination in gunshot wound cases is an important part of forensic practice for investigation and disclosure of crimes as well as in court proceedings, both for criminal and civil cases. This examination allows confirmation such as whether the case is indeed a gunshot wound, an entry wound and an exit wound, the diameter of the bullet and the caliber and the type of firearm used, the distance of the shot, the direction of the shot, the position of the victim and shooter, the number of times the victim was shot, the determination of the wound, and the severity of the injury [3], [4].

Penetrating wounds to the chest are one of the most difficult cases to treat due to varied clinical presentations that require adjustment of management. This can happen among others because of the different types of bullets and weapons used. For example, injuries from air rifle bullets do not show tattoo seams because there is no gunpowder burning process from the bullet. However, these 
injuries can cause significant morbidity and mortality. The treatment depends on the degree of injury and the organs involved. High rates of morbidity are associated with gunshot wounds leading to the heart by $20-30 \%$. Meanwhile, about $30-60 \%$ of morbidity is caused by penetrating wound [5], [6].

The mortality rate from gunshot wounds is very high. The typical clinical appearance of a gunshot wound makes it easier for the examiner to locate the entry and exit routes of the gunshot wound. In some cases of gunshot wounds, doctors often misdiagnose, especially in cases of shootings with the use of nontypical ammunition or in long-range shots [4]. A typical gunshot wound involves serious disruption of the soft tissue, bone, and cartilage components surrounding the gunshot wound. Surrounding tissue factors also have an important role in the morphology of the injury, in particular the density, and elasticity of the traumatized tissue. Early treatment and the decision to extract the bullet are very important for the survival of the patient [5], [7], [8].

\section{Case Report}

A man, 58 years old, was reported as a shooting victim, with brown skin color, $170 \mathrm{~cm}$ body length and weighing $60 \mathrm{~kg}$. Gunshot wound was found in the middle back of the left side. Based on the victim's statement, the victim was on his way home from his banana plantation in Seulimum while riding a motorcycle. The victim was shot with an air rifle shortly after the victim rode a motorcycle on his way home. Previously, the victim also heard gunshots from the corn field not far from the victim's position at that time. At the time of the incident, the victim fell from the motorbike, but the victim was still conscious. Then, the victim tried to hide behind the bushes while calling the family for help. The victim was evacuated by the village head and taken to the Aceh Besar Regional Hospital. After receiving first aid from the hospital, the victim was referred to the Regional General Hospital Dr. Zainoel Abidin (RGHZA) to get further treatment.

The victim was examined at the emergency room at RGHZA with vital signs: Blood pressure $107 / 85 \mathrm{mmHg}$, pulse 82 beat $/ \mathrm{min}$, breathing 18 times/min, body temperature $36.6^{\circ} \mathrm{C}$, and level of consciousness with Glasgow Coma Scale Eye-4, Motoric-6, and Verbal-5 (E4M6V5). Neurological examination revealed isochoral pupils ( $3 \mathrm{~mm} / 3 \mathrm{~mm}$ ), direct and indirect light reflexes in both eyes were positive, motor and sensory functions were within normal limits, no pathological reflexes were found. Physical examination revealed a wound in the posterior thoracic

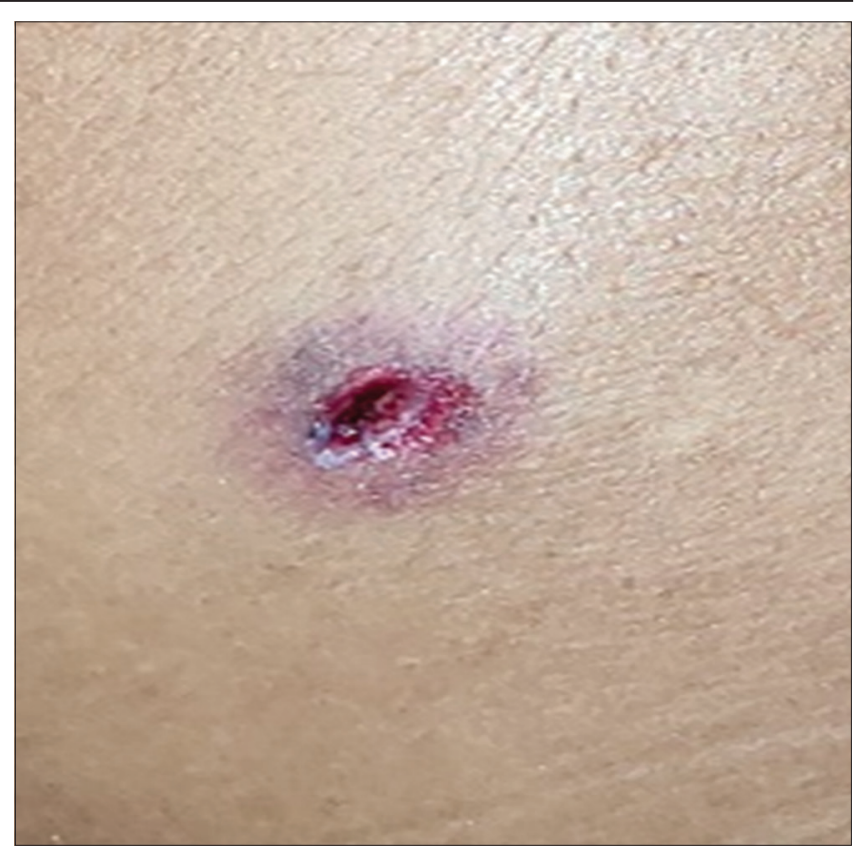

Figure 1: A gunshot wound to the left back with a round shape with blisters, no tattoo seams around the wound

region about the left $11^{\text {th }}$ thoracic vertebra. On forensic physical examination, there was a gunshot wound to the left back with a round shape with blisters, no tattoo seams around the wound and no penetrating wound on the other side (Figure 1). Based on the radiological examination, two radio-opaque cylindrical were found, separated from one another with one located higher, on the left hemithorax (Figures 2 and 3).

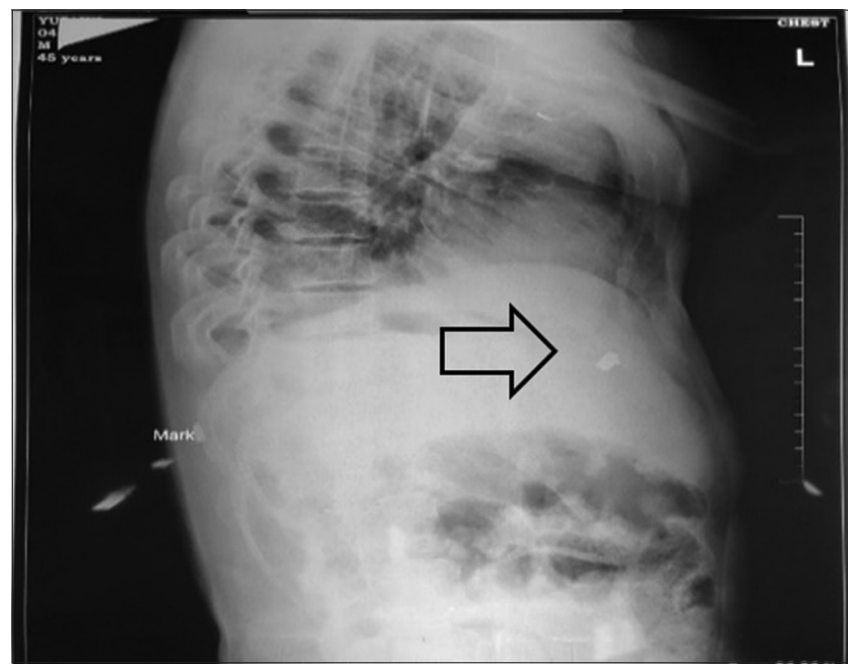

Figure 2: Lateral chest $X$-ray showing a radio-opaque shadow (arrow) at the front side of hemithorax

The victim immediately underwent an emergency foreign body extraction operation. The action uses guiding $\mathrm{C}$-arm imaging. In intra-operative findings, there was a foreign body in the region of the left thoracic wall and a laceration in the left inferior lobe of the lung, so lung repair was performed (Figures 4 and 5). At present, the patient is being treated at the high care unit (HCU) RGHZA with stable hemodynamics. 


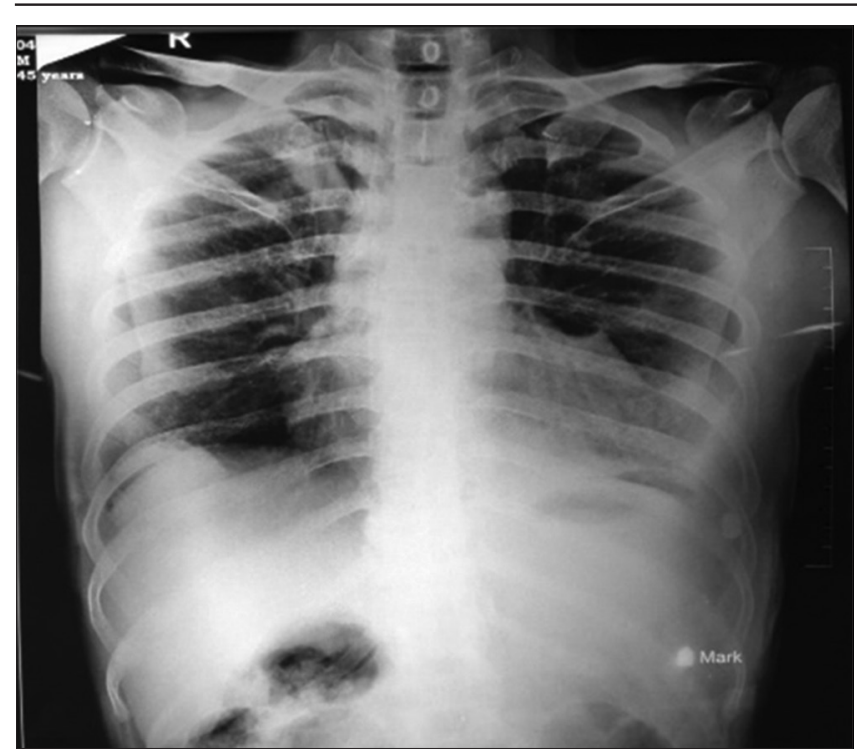

Figure 3: Posteroanterior chest $X$-ray showing a radio-opaque shadow (mark) at the lower left hemithorax

\section{Discussion}

The bullet removal in this case was done through fluoroscopy-guided thorachostomy exploration, especially targeting the left lower lateral lobe of thorax region. The procedure was followed by the open reduction and internal fixation of fractured sixth rib, lung repair, and water seal drainage installment. The bullet, assumed as foreign body or corpus alienum, was left close to the front side of left thorax, so the deep extraction was pivotal. However, the procedures were only possibly done under general anesthesia to take off the bullet and at same time, save the patient who will be further examined by forensic medicine department regarding the gunshot. The anesthesia procedure was supported by endotracheal tube as the standard airway device in intubation upholding the breathing amid the unconsciousness phase [9].

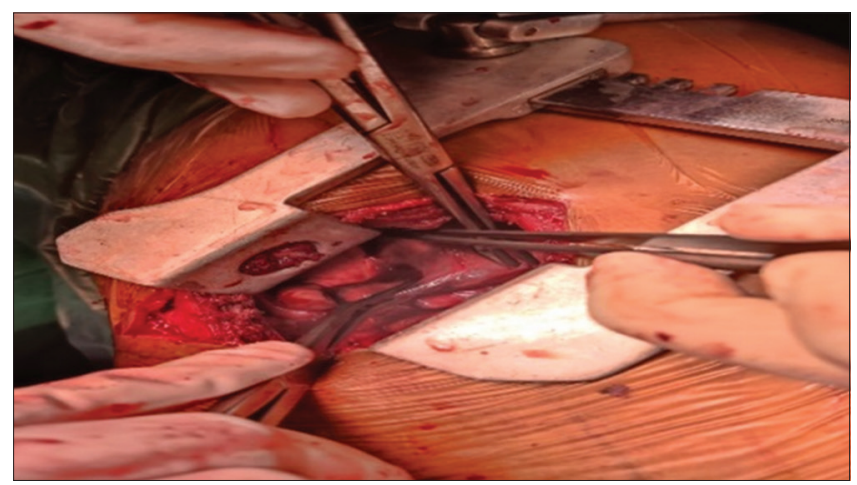

Figure 4: Intra-operation foreign body extraction

The weapon used in this case is an air rifle. Air rifles are weapons that use the pneumatic principle that fires bullets using compressed air or certain gases. The victim admitted that he was shot from behind, so the exact distance from the shooter cannot be known. Gunshot wounds do not penetrate to other parts of the body, so they are categorized as entry gunshot wounds. The wound was accompanied by a seam of abrasions and no tattoo seams, soot, or fire were found, so it is suspected that the patient was shot with an air rifle regardless of the shooter's distance from the victim (Figure 2). Tattoo seams, soot, and fire can be found on gunshot wounds caused by gunpowder burning. Long-range gunshot wounds occur when the distance between the muzzle of the weapon and the victim is beyond the range of the gunpowder. Guns that are frequently maintained, such as with regular lubricating oil, result in gunshots producing grease seam [10], [11].

A close-range gunshot wound occurs when the distance between the muzzle of the weapon and the victim's body is still within the range of the gunpowder or the range of soot or fire. The range of gunpowder indicates close range, while the range of soot and fire indicates very close range. Typical signs of injury can be observed in the area around the wound, including tattoo seams, soot seams, and fire seams. Tattoo seams can be identified on gunshot wounds (usually with handguns) from a muzzle distance of about $60 \mathrm{~cm}$, with gunpowder spots that are not burned or not completely burned. The soot indicates that the distance from the muzzle of the weapon to the victim is about $30 \mathrm{~cm}$, showing a red area or a charred condition due to gunfire with soot or smoke visible around the wound. Meanwhile, the seams of fire were found when the muzzle of the weapon was about $15 \mathrm{~cm}$ from the victim with the surrounding wounds showing signs of fire [12], [13].

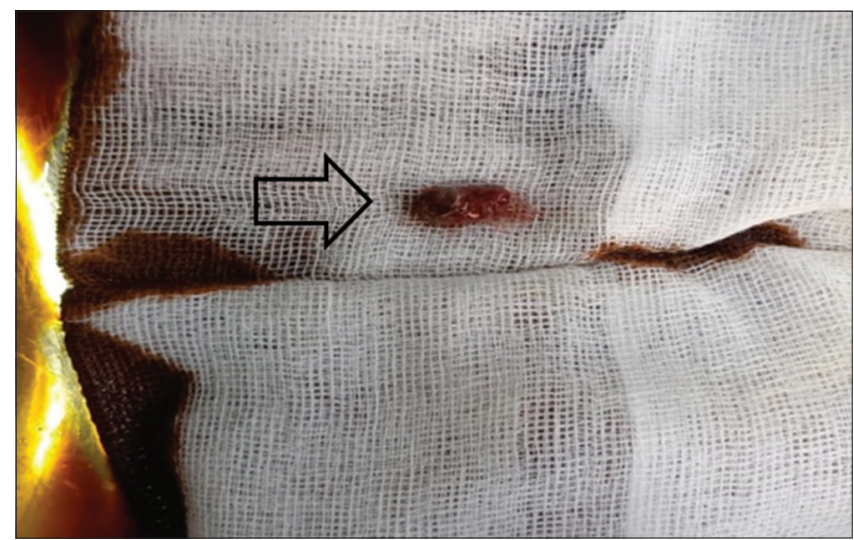

Figure 5: Foreign body was found as gun projectile (arrow)

A contact gunshot wound can be identified by the barrel injury, which is a wound caused by the tip of the gun barrel sticking to the victim's skin when the firearm is fired, forming pressure sores that surround the seam of the blister with protrusions around it. Under certain conditions, long-range gunshot wounds can also be found in victims who were shot at close range or very close if the victim uses something as a barrier or shield over the skin of the target. The barriers in question, for example, belts, thick clothing, or helmets, allow bullets, unburnt gunpowder, soot, and fire to be contained to further injure the victim. If the shot hits the body of a victim who is wearing thick clothing, it 
can be observed that there is smoke, gunpowder, fire, and metal fragments stuck in the clothes; trapped by clothing and clothing fibers carried by the bullet into the gunshot wound [12], [13]. The victim said that he was wearing a jacket while riding a motorbike at the time of the shooting, which meant the patient's body was better protected from the gunfire.

The identification of a typical or consistent shot residue must take into account both the chemical composition and morphology of the bullet particles being examined. The gold standard examination for gunshot residue analysis is examination using a scanning electron microscope with energy dispersive X-ray spectrometer. The examination can confirm the presence of the main mixture, which is typical as a "typical shot residue," that is, if the three heavy metal compounds are lead-lead azide or styphnate, antimony-antimony trisulfide, and barium-barium nitrate. Findings of one or more, but not all three were marked as "consistent shot residue" [3]. The working mechanism of an air rifle is to use high pressure from air or gas to throw a bullet out of the barrel at high speed. The high pressure on the air gun is obtained by converting liquid $\mathrm{CO}_{2}$ into gas in a constant volume chamber. Air rifle injuries are often minimal than firearms. Wounds are often found to be varied, in the form of superficial trauma to the skin, subcutis, and muscle tissue [13].

It is important for the surgeon to provide care, to excise carefully during surgical treatment of gunshot wounds and to send them for analysis and histological tracing of gunshot residue particles, with a note not to place the excised tissue in alcohol or formalin to avoid washing the skin surface. The procedure is of course assisted by an anesthesiologist. The clinical doctor must pay close attention to the situation after the shooting incident and obtain as much information as possible from the victim, as well as examine the victim's clothing carefully to ensure the entry of bullets and the size of the tear caused [14]

Physical examination of the victim revealed a wound in the posterior thoracic region about the $11^{\text {th }}$ left thoracic vertebra. Based on the results of the radiographic examination of the posteroanterior and lateral chest radiographs, two cylindrical opaque figures were found in the left hemithorax. Forensic examination of the victim showed that there was an entrance gunshot wound to the left side of the back that was round or oval in shape, accompanied by seams of abrasions around the wound, no seams of tattoos, soot, or fire were found and there was no external gunshot wound. The shooting was caused by an air rifle. Air rifles tend to inflict minimal injuries and are not accompanied by a soot seam from bullets that do not involve the burning of gunpowder.

\section{Conclusion}

Multidisciplinary cooperation in disclosing gunshot wounds to living victims is very much needed. The collaboration of clinical forensic medicine experts, anesthesiologists, and surgeons can facilitate tracing the consequences of injuries, handling victims, and revealing cases. Clinical forensic evidence of course continues to evolve in accordance with advances in medical technology. The better the proof method, the easier it is to find the desired evidence. Anesthesia and surgical procedures can be used as an alternative to forensic evidence in clinical cases.

\section{References}

1. Meilia PD, Freeman MD, Herkutanto, Zeegers MP. A review of the diversity in taxonomy, definitions, scope, and roles in forensic medicine: Implications for evidence-based practice. Forensic Sci Med Pathol. 2018;14(4):460-65. https://doi.org/10.1007/ s12024-018-0031-6

PMid:30276619

2. Stefanopoulos PK, Pinialidis DE, Hadjigeorgiou GF, Filippakis KN Wound ballistics 101: The mechanisms of soft tissue wounding by bullets. Eur J Trauma Emerg Surg. 2015;43(5):579-86. https:// doi.org/10.1007/s00068-015-0581-1

\section{PMid:26470704}

3. Shrestha R, Kanchan T, Krishan K. Gunshot wounds forensic pathology. In: StatPearls. Treasure Island, FL: StatPearls Publishing; 2021

4. Jakjovski Z, Stankov A, Pavlovski G, Bitoljanu N, Srpanova VB, Cakar L. Misdiagnosed injuries of unusual gunshot wounds in the clinical forensic practice. Int J For Sci. 2020;5(2):1-4

5. Ganguly T, Sandeep KS. Thoracic gunshot wound: A report of 3 cases and review of management. Prensa Med. 2015;105(5):1-5.

6. Alakhfash AA, Alqwaee A, Almesned A. Percutaneous removal of air-bullet gunshot: Case report and literature review. Egypt Hear J. 2020;72(1):21. https://doi.org/10.1186/ s43044-020-00055-3 PMid:32367156

7. Onajin-Obembe B, Kushimo O, Essien O. Gunshot facial injury: A multi-disciplinary management. South African J Anaesth Analg. 2007;13(6):13-5.

8. Denis B. Perioperative management of wounds in combat area. J Anesth Intensive Care Med. 2018;7(1):555705. https://doi. org/10.19080/JAICM.2018.07.555705

9. Ahmed RA, Boyer TJ. Endotracheal tube. In: StatPearls Treasure Island, FL: StatPearls Publishing; 2021.

10. Giovine S, Romano L. Gunshot wounds: Ballistics and imaging findings. Semin Ultrasound CT MRI. 2019;40(1):25-35. https:// doi.org/10.1053/j.sult.2018.10.018 PMid:30686364

11. Avraham JB, Frangos SG, di Maggio CJ. The epidemiology of firearm injuries managed in US emergency departments. Inj Epidemiol. 2018;5(1):36-8. https://doi.org/10.1186/ 


\section{s40621-018-0168-5}

12. Najari $F$, Jafari $H$, Alimohammadi AM, Naari D. The importance of Victim's clothes in gunshot wounds. J Emerg Pract Trauma. 2020;6(2):73-6.

13. Dumenčić B, Rajc J, Pavoković D, Damjanović T. Fatal injury by air gun: A case report. Egypt J Forensic Sci. 2020;10(7):1-4.

14. Branas CC, Han S, Wiebe DJ. Alcohol use and firearm violence. Epidemiol Rev. 2016;38(1):35-45. https://doi.org/10.1093/ epirev/mxv010

PMid:26811427 